\title{
Clavien classification in urology: Is there concordance among post-graduate trainees and attending urologists?
}

\author{
Mohamed A. Elkoushy, MD; Murilo A. Luz, MD; Tarik Benidir, MD; Saad Aldousari MD; Armen G. Aprikian, \\ MD, FRCSC; Sero Andonian, MD, FRCSC, FACS
}

Division of Urology, Department of Surgery, McGill University Health Centre, McGill University, Montreal, QC

See related commentary by Declan Murphy at cuaj.ca

Cite as: Can Urol Assoc J 2013;7:7(5-6):179-84. http://dx.doi.org/10.5489/cuaj.505

\section{Abstract}

Purpose: We assess the variations between post-graduate trainees (PGTs) and attending urologists in applying the Revised ClavienDindo Classification System (RCCS) to urological complications. Methods: Twenty postoperative complications were selected from urology service Quality Assurance meeting minutes spanning 1 year at a tertiary care centre. The cases were from adult and pediatric sites and included minor and major complications. After a briefing session to review the RCCS, the survey was administered to 16 attending urologists and 16 PGTs. Concordance rates between the two groups were calculated for each case and for the whole survey. Inter-rater agreement was calculated by kappa statistics.

Results: There was good overall agreement rate of $81 \%$ (range: $30-100)$ when both groups were compared. Thirteen of the 20 cases $(65 \%)$ held an agreement rate above $80 \%(k=0.753, p<0.001)$ including $3(15 \%)$ cases with $100 \%$ agreement. There were only 2 cases where the scores given by PGTs were significantly different from that given by attending urologists $(p \leq 0.03)$. There was no significant difference between both groups in terms of overall RCCS grades $(p=0.12)$. When all participants were compared as one group, there was good overall inter-rater agreement rate of $75 \%$ $(k=0.71)$. Although the percent of overall agreement rate among PGTs was higher than the attending urologists $(82 \%[k=0.79]$ vs. $69 \%$ [ $k=0.64])$, this was not significantly different $(p=0.68)$. Conclusion: There was good overall agreement among PGTs and attending urologists in application of the RCCS in urology. Therefore, it is appropriate for PGTs to complete the Quality Assurance meeting reports.

\section{Introduction}

The Revised Clavien-Dindo Classification System (RCCS) is based on the type of treatment needed to correct an operative complication within a 90 -day period. ${ }^{1}$ It has been applied and validated for elective general surgical procedures $^{2,3}$ and was significantly correlated with complexity of surgery and length of hospitalization. ${ }^{2}$ In addition, the RCCS has been validated for a range of urological procedures, such as radical cystectomy, ${ }^{4}$ radical prostatectomy, ${ }^{5,6}$ nephrectomy ${ }^{7}$ and percutaneous renal surgery. ${ }^{8,9}$ Therefore, the RCCS has become the "gold standard" of reporting postoperative complications. ${ }^{10}$

However, the RCCS is not without shortcomings. One of the limitations of the RCCS is that subjective interpretation of postoperative complications plays a role in creating variability in the grade assignment. For example, rectal injury during laparoscopic radical prostatectomy was graded differently by different groups; grade I (prolonged hospital stay) versus grade III (intra-operative repair under general anaesthesia). ${ }^{11}$ Moreover, sub-classifications of grades III and IV make room for inter-rater variability since one intervention may be performed under local anesthesia at one institution, while it is performed under general anesthesia in another. ${ }^{10,12}$ Furthermore, a patient with a single complication may not be differentiated from another with multiple complications, especially when both complications are of the same grade. Finally, two patients with the same complication, such as deep-vein thrombosis, may be managed differently in different institutions (anticoagulation Gll vs. filter GIII).

Since Quality Assurance case presentations are usually prepared by post-graduate trainees (PGTs) in academic centres, it was hypothesized that PGTs, compared with attending urologists, may be more comfortable in using the RCCS. However, attending urologists have more experience in urological surgeries and their complications. Therefore, there may be differences in interpreting the RCCS between PGTs and attending urologists. Currently, there is no data available regarding inter-rater variability in RCCS grading among urology PGTs and attending urologists. Therefore, the aim of the present study was to compare the agreement rate between urology PGTs and attending urologists applying the RCCS. 
Elkoushy et al.

\section{Methods}

Quality Assurance meeting minutes from the division of urology of a tertiary academic centre over a 12-month period were collected. After removing all identifying information (patient name, identification number, hospital name and surgeon), 20 cases of postoperative complications were selected which reflected common urological practice, including adult and pediatric procedures. The case scenarios were chosen to include minor and major complications.

During Department of Urology grand rounds, the RCCS was reviewed with illustrative examples (Appendix 1). ${ }^{2}$ Questions from participants were answered to clarify the grading system. All participants were handed out the answer sheets. All participants were asked to indicate whether they were attending urologists or PGT, in addition to the post-graduate year level. Then, the 20 case scenarios were sequentially presented through a PowerPoint presentation (Appendix 2). Participants were advised not to discuss cases with their colleagues prior to filling out the grade for each case. Three minutes were provided after each case to allow participants to think and fill out the answer sheet. At the end of the session, all answer sheets were collected and data were tabulated.

Data analysis was done using the commercially available Statistical Package of Social Sciences for windows (SPSS, Chicago, IL), version 17 together with the online kappa calculator (http://justusrandolph.net/kappa/), accessed on June 14, 2012. Categorical variables were presented in terms of frequencies and percentages. Fisher's exact test was used to compare categorical variables with two-tailed $p<0.05$ considered statistically significant. Fleiss' kappa statistics ${ }^{13}$ (a chance-adjusted measure of agreement) was calculated to assess inter-rater variability among individuals within each group and for the whole cohort of participants. Furthermore, intra- and inter-group differences were also assessed. Kappa statistical value of 0.00 represented agreement by chance alone, while a kappa value of 1.00 represented almost perfect agreement. Values of less than 0.00 indicated poor agreement; 0.00 to 0.20 , slight agreement; 0.21 to 0.40 , fair agreement; 0.41 to 0.60 , moderate agreement; 0.61 to 0.80 , substantial or good agreement; and 0.81 to 1.00 , excellent agreement. ${ }^{14}$

\section{Results}

The 20 cases were graded by 32 participants; 16 attending urologists and 16 PGTs in post-graduate years 3 to 7 . There was no significant difference in the distribution of the RCCS grades between PGTs and attending urologists (Fig. 1). When PGTs were compared with attending urologists as groups, there was good overall agreement rate of 81\% (range: $30-100)$. Thirteen of the $20(65 \%)$ cases had an agreement rate above $80 \%$ (range: $81-100$ ), including 3 (15\%) cases with $100 \%$ agreement (Table 1$)$. Furthermore, there was no significant difference between both groups in terms of overall grading of complications $(p=0.12)$, with Fleiss' kappa statistics revealing good agreement between both groups $(k=0.753, p<0.001)$. In two cases, the grades given by PGTs were significantly different from that given by attending urologists $(p \leq 0.03)$. In case $8,94 \%$ of PGTs had graded the complication either grade IIIb (94\%) or higher, while attending urologists graded it as grade $\mathrm{IIIb}(75 \%)$ or lower $(p=0.03)$. In case 15 , PGTs gave a significantly lower grades (grade I [75\%] and II [25\%]) than attending urologists (grades I [25\%], II [50\%], and III [25\%]) $(p=0.01)$ (Table 1).

When all respondents were pooled together, the percent of overall agreement among all raters was $75 \%$ (range: 30-100) and the Fleiss' kappa statistics showed good interrater agreement with a value of $0.71(95 \% \mathrm{Cl}$ : 0.68-0.76) (Table 2, Table 3). When comparing low grades (grades I and II) and high grades (grades III-V), there was still overall good agreement $81 \%(\mathrm{k}=0.77, p=0.09)$ (Fig. 2). When the subgroups of grades III and IV were combined to form one group each, the agreement was improved among PGTs $(0.86, \mathrm{k}=0.83)$, attending urologists $(0.77, \mathrm{k}=0.71)$ and overall group $(0.80, \mathrm{k}=0.76)$. There was still no significant difference between both groups in terms of overall grading of complications $(p=0.15)$.

Overall agreement among PGTs tended to be higher than attending urologists (82\% vs. $69 \%$ ) and overall Fleiss' kappa values for inter-rater reliability was higher for PGTs than attending urologists (0.79 vs. 0.64 ) (Table 2 , Table 3 ). However, these differences were not significant $(p>0.05)$. PGTs had over $80 \%$ concordance for $12(60 \%)$ of cases, including $6(30 \%)$ cases with $100 \%$ agreement compared with $8(40 \%)$ cases with over $80 \%$ concordance, including $5(25 \%)$ cases with $100 \%$ agreement for attending urologists $(p>0.05)$.

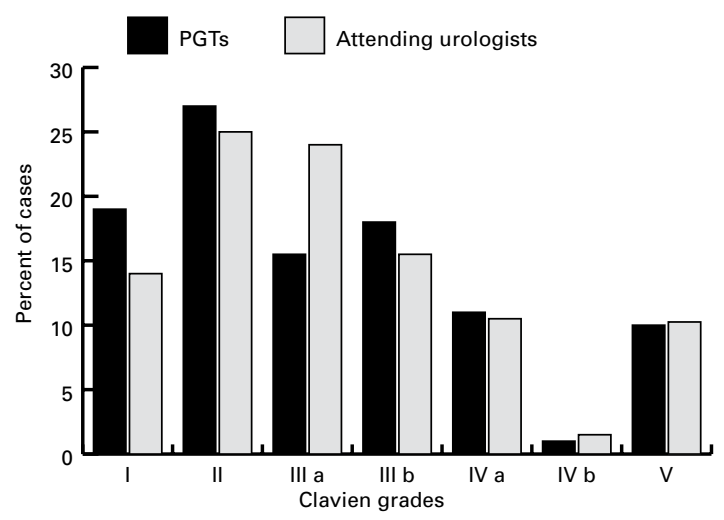

Fig. 1. Revised Clavien-Dindo Classification System Grading according to group (post-graduate trainnes vs. attending urologists); $p=0.36$. 


\begin{tabular}{|c|c|c|c|c|c|}
\hline $\begin{array}{l}\text { Case } \\
\text { No. }\end{array}$ & $\begin{array}{l}\text { RCCS } \\
\text { Grade }\end{array}$ & PGTs & $\begin{array}{l}\text { Attending } \\
\text { urologists }\end{array}$ & $\begin{array}{c}p \\
\text { value }\end{array}$ & $\begin{array}{c}\text { Agreement } \\
\text { between groups }\end{array}$ \\
\hline \multirow{2}{*}{1} & II & $10(62.5)$ & 7 (43.75) & \multirow{2}{*}{0.48} & \multirow{2}{*}{81.3} \\
\hline & III a & 6 (37.5) & $9(56.25)$ & & \\
\hline \multirow{2}{*}{2} & III a & $0(00)$ & $1(6.25)$ & \multirow{2}{*}{1.00} & \multirow{2}{*}{93.8} \\
\hline & III b & $16(100)$ & $15(93.75)$ & & \\
\hline \multirow{2}{*}{3} & IV b & $1(6.25)$ & $0(00)$ & \multirow{2}{*}{1.00} & \multirow{2}{*}{93.8} \\
\hline & V & 15 (93.75) & $16(100)$ & & \\
\hline \multirow{3}{*}{4} & 1 & 2 (12.5) & $0(00)$ & \multirow{3}{*}{0.48} & \multirow{2}{*}{87.5} \\
\hline & III a & $14(87.5)$ & $16(100)$ & & \\
\hline & II & $0(00)$ & $3(18.75)$ & & \\
\hline \multirow[t]{3}{*}{5} & IV a & 15 (93.75) & $12(75)$ & \multirow[t]{3}{*}{0.11} & \multirow[t]{3}{*}{81.3} \\
\hline & IV b & $1(6.25)$ & $1(6.25)$ & & \\
\hline & III a & $14(87.5)$ & 15 (93.75) & & \\
\hline \multirow[t]{2}{*}{6} & III b & 2 (12.5) & $0(00)$ & \multirow[t]{2}{*}{0.12} & \multirow[t]{2}{*}{87.5} \\
\hline & IV a & $0(00)$ & $1(6.25)$ & & \\
\hline 7 & II & $16(100)$ & $16(100)$ & 1.00 & 100 \\
\hline \multirow{3}{*}{8} & III a & $0(00)$ & $4(25)$ & \multirow{3}{*}{0.03} & \multirow{3}{*}{68.8} \\
\hline & III b & 15 (93.75) & $12(75)$ & & \\
\hline & IV a & $1(6.25)$ & $0(00)$ & & \\
\hline \multirow{2}{*}{9} & I & 15 (93.75) & $13(81.25)$ & \multirow{2}{*}{0.60} & \multirow{2}{*}{87.5} \\
\hline & II & $1(6.25)$ & $3(18.75)$ & & \\
\hline \multirow{2}{*}{10} & I & $0(00)$ & $1(6.25)$ & \multirow{2}{*}{1.00} & \multirow{2}{*}{93.8} \\
\hline & II & $16(100)$ & 15 (93.75) & & \\
\hline \multirow{3}{*}{11} & I & $14(87.5)$ & $8(50)$ & \multirow{3}{*}{0.05} & \multirow{2}{*}{62.5} \\
\hline & III a & 2 (12.5) & $8(50)$ & & \\
\hline & III a & $0(00)$ & $1(6.25)$ & & \\
\hline \multirow[t]{2}{*}{12} & III b & $15(93.75)$ & 14 (87.5) & \multirow[t]{2}{*}{0.49} & 93.8 \\
\hline & IV a & $1(6.25)$ & $1(6.25)$ & & \\
\hline
\end{tabular}

\section{Discussion}

The RCCS has been validated and adapted as a standardized method of reporting complications across various surgical sub-specialties. ${ }^{3}$ There has been an exponential rise in the

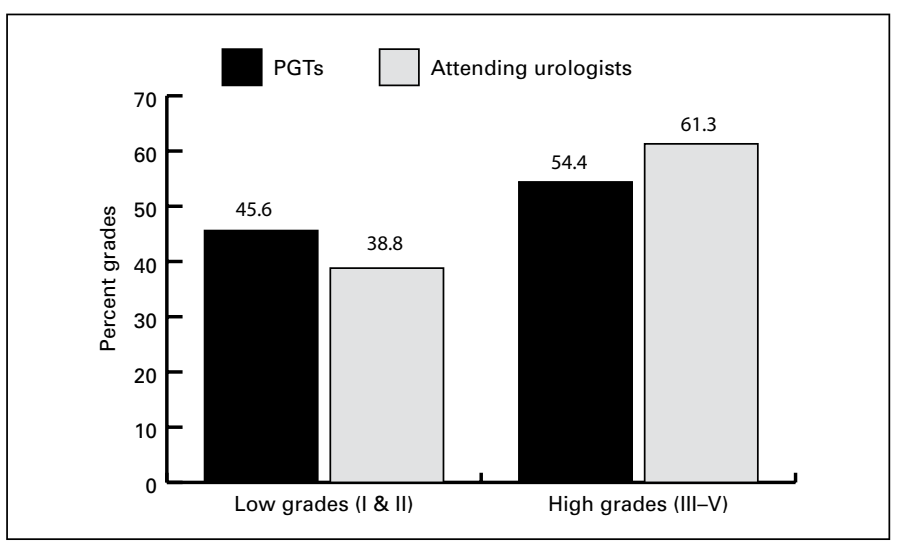

Fig. 2. Inter-group differences between post-graduate trainees and attending urologists using the contracted Revised Clavien-Dindo Classification System; $p=0.09$.

\begin{tabular}{|c|c|c|c|c|c|}
\hline $\begin{array}{l}\text { Case } \\
\text { No. }\end{array}$ & $\begin{array}{l}\text { RCCS } \\
\text { Grade }\end{array}$ & PGTs & $\begin{array}{l}\text { Attending } \\
\text { urologists }\end{array}$ & $\begin{array}{c}p \\
\text { value }\end{array}$ & $\begin{array}{c}\text { Agreement } \\
\text { between groups }\end{array}$ \\
\hline \multirow{5}{*}{13} & $I$ & $0(00)$ & $1(6.25)$ & \multirow{5}{*}{0.06} & \multirow{5}{*}{56.5} \\
\hline & II & $13(81.25)$ & $7(43.75)$ & & \\
\hline & III a & 2 (12.5) & 7 (43.75) & & \\
\hline & III b & $1(6.25)$ & $0(00)$ & & \\
\hline & IV a & $0(00)$ & $1(6.25)$ & & \\
\hline \multirow{3}{*}{14} & II & $16(100)$ & $14(87.5)$ & \multirow{3}{*}{0.23} & \multirow{3}{*}{87.5} \\
\hline & III a & $0(00)$ & $1(6.25)$ & & \\
\hline & IV b & $0(00)$ & $1(6.25)$ & & \\
\hline \multirow{4}{*}{15} & 1 & $12(75)$ & $4(25)$ & \multirow{4}{*}{0.01} & \multirow{4}{*}{50.0} \\
\hline & II & $4(25)$ & $8(50)$ & & \\
\hline & III a & $0(00)$ & $2(12.5)$ & & \\
\hline & IV a & $0(00)$ & 2 (12.5) & & \\
\hline \multirow{5}{*}{16} & I & $1(6.25)$ & $1(6.25)$ & \multirow{5}{*}{0.26} & \multirow{5}{*}{30.0} \\
\hline & II & $10(62.5)$ & $6(37.5)$ & & \\
\hline & III a & $0(00)$ & $3(18.75)$ & & \\
\hline & III b & $2(12.5)$ & $2(12.5)$ & & \\
\hline & IV a & $3(18.75)$ & $4(25)$ & & \\
\hline \multirow[t]{2}{*}{17} & V & $16(100)$ & $16(100)$ & \multirow[t]{2}{*}{1.00} & \multirow[t]{2}{*}{100} \\
\hline & III a & $11(68.75)$ & $9(56.25)$ & & \\
\hline \multirow[t]{2}{*}{18} & III b & $5(31.25)$ & 6 (37.5) & \multirow[t]{2}{*}{0.43} & \multirow[t]{2}{*}{68.8} \\
\hline & IV a & $0(00)$ & $1(6.25)$ & & \\
\hline \multirow[t]{2}{*}{19} & I & $16(100)$ & $16(100)$ & \multirow[t]{2}{*}{1.00} & \multirow[t]{2}{*}{100} \\
\hline & II & $0(00)$ & $1(6.25)$ & & \\
\hline \multirow[t]{2}{*}{20} & IV a & 15 (93.75) & $12(75)$ & \multirow[t]{2}{*}{0.25} & \multirow[t]{2}{*}{75.0} \\
\hline & IV b & $1(6.25)$ & $3(18.75)$ & & \\
\hline
\end{tabular}

use of this RCCS to report complications in the published literature. Moreover, the European Urological Association highly recommended the use of this classification system to standardize the report of complications in the urologic literature. ${ }^{15}$ However, subjective interpretation of postoperative complications may result in inter-rater variability. ${ }^{11}$ In academic centres, Quality Assurance case presentations are prepared by PGTs. Therefore, it was hypothesized that PGTs may be more comfortable in using the RCCS when compared with attending urologists. On the other hand, PGTs, when compared with attending urologists, may assign a different RCCS grade since they have less experience in urological surgeries and their complications. Therefore, we compare agreement rates in RCCS among urology PGTs and attending urologists.

In the present study, there was a good overall agreement rate of $81 \%(k=0.753, p<0.001)$ between PGTs and attending urologists. Similarly, in the field of general surgery, Clavien and colleagues found a good agreement rate of $89 \%$ among raters across 7 international centres when 11 difficult scenarios were presented. ${ }^{3}$ In addition, inter-rater agreement for the RCCS has been evaluated for orthopedic 
Elkoushy et al.

\begin{tabular}{lccc}
\hline \multicolumn{3}{l}{$\begin{array}{l}\text { Table 2. Inter-rater agreement among post-graduate } \\
\text { trainees, attending urologists and all respondents }\end{array}$} \\
\hline & PGTs & $\begin{array}{c}\text { Attending } \\
\text { urologists }\end{array}$ & All respondents \\
\hline 1 & 0.50 & 0.48 & 0.48 \\
2 & 1.00 & 0.88 & 0.94 \\
3 & 0.88 & 1.00 & 0.94 \\
4 & 0.77 & 1.00 & 0.86 \\
5 & 0.88 & 0.58 & 0.72 \\
6 & 0.77 & 0.88 & 0.82 \\
7 & 1.00 & 1.00 & 1.00 \\
8 & 0.88 & 0.60 & 0.72 \\
9 & 0.88 & 0.68 & 0.77 \\
10 & 1.00 & 0.88 & 0.94 \\
11 & 0.77 & 0.47 & 0.56 \\
12 & 0.88 & 0.76 & 0.82 \\
13 & 0.66 & 0.35 & 0.46 \\
14 & 1.00 & 0.76 & 0.88 \\
15 & 0.60 & 0.30 & 0.38 \\
16 & 0.41 & 0.21 & 0.30 \\
17 & 1.00 & 1.00 & 1.00 \\
18 & 0.54 & 0.43 & 0.49 \\
19 & 1.00 & 1.00 & 1.00 \\
20 & 0.88 & 0.58 & 0.72 \\
\hline Overall & 0.82 & 0.69 & 0.75 \\
\hline PGTs: post-graduate trainees. & & \\
\hline & & & \\
\hline
\end{tabular}

complications post-hip preservation surgery. Excellent reliability of this system was shown where the inter-rater and intra-rater agreement rates were $86 \%$ and $89 \%$, respectively. ${ }^{16}$ However, the authors modified the RCCS to remove the sub-divisions in grades III and IV.

For cases with less than $80 \%$ agreement (cases 8, 13, $15,16,18,20$, except for 11), there were more than two grades assigned mainly in the sub-divisions of grades III and IV (Table 1). Part of this variation in grading these cases could be due to subjective interpretation of the different subclassifications of grades III and IV, as has been previously mentioned. ${ }^{12,17}$ This is where subjective interpretation influences the different subdivisions in grades III and IV. This is because interventional procedures may be performed under local anesthesia in one centre, and under general anesthesia in another (grade III-a vs. grade III-b). Furthermore, there may be different institutional policies regarding intensive care unit (ICU) admissions for observing postoperative intubated patients with sepsis (grade III-b vs. IV). ${ }^{10}$ This was the reason for the discrepancy in grading case 16, where the patient with suspected bladder-perforation post-ureteroscopy was observed intubated in the ICU (Table 1). When grades III and IV subgroups were combined into one group each, the concordance rates improved among PGTs $(0.86, \mathrm{k}=0.83)$, attending urologists $(0.77, \mathrm{k}=0.71)$ and the overall group $(0.80, k=0.76)$. This highlights one of the limitations of the

\begin{tabular}{lccc}
\hline \multicolumn{4}{l}{$\begin{array}{l}\text { Table 3. Fleiss' kappa for inter-rater reliability among post- } \\
\text { graduate trainees, attending urologists and all respondents }\end{array}$} \\
\hline & PGTs & $\begin{array}{c}\text { Attending } \\
\text { urologists }\end{array}$ & All respondents \\
\hline 1 & 0.41 & 0.39 & 0.40 \\
2 & 1.00 & 0.85 & 0.93 \\
3 & 0.85 & 1.00 & 0.93 \\
4 & 0.73 & 1.00 & 0.88 \\
5 & 0.85 & 0.50 & 0.67 \\
6 & 0.73 & 0.85 & 0.79 \\
7 & 1.00 & 1.00 & 1.00 \\
8 & 0.85 & 0.53 & 0.67 \\
9 & 0.85 & 0.62 & 0.74 \\
10 & 1.00 & 0.85 & 0.93 \\
11 & 0.73 & 0.38 & 0.48 \\
12 & 0.85 & 0.72 & 0.79 \\
13 & 0.60 & 0.24 & 0.36 \\
14 & 1.00 & 0.72 & 0.86 \\
15 & 0.53 & 0.18 & 0.28 \\
16 & 0.31 & 0.08 & 0.19 \\
17 & 1.00 & 1.00 & 1.00 \\
18 & 0.47 & 0.33 & 0.41 \\
19 & 1.00 & 1.00 & 1.00 \\
20 & 0.85 & 0.50 & 0.67 \\
\hline Overall & $\mathbf{0 . 7 9}$ & $\mathbf{0 . 6 4}$ & $\mathbf{0 . 7 1}$ \\
\hline PGTs: post-graduate trainees. & & \\
\hline & & & \\
\hline
\end{tabular}

RCCS in that grades III and IV have subdivisions that reduce inter-rater agreement. ${ }^{10,12}$

There were no significant differences between both groups in terms of overall grading of complications $(p=0.12)$. In two cases, the grades given by PGTs were significantly different from that given by attending urologists $(p \leq 0.03)$ (Table 1 ). In case 15 , PGTs gave a significantly lower score (grade I and II by $75 \%$ and $25 \%$, respectively) than attending urologists (grade I, II, and over in 25, 50, and $25 \%$, respectively) $(p=0.01)$. However, the reverse was seen in case 8 where $94 \%$ of PGTs had graded the complication significantly higher than attending urologists $(p=0.03)$. Therefore, no clear pattern emerged in overall grading between PGTs and attending urologists.

When compared with attending urologists, PGTs showed a trend towards a higher overall agreement rate $(0.82 \mathrm{vs}$. $0.69, p=0.68$ ) and a higher overall Fleiss' kappa value for inter-rater reliability $(0.79$ vs. 0.64$)$. Although these differences were not significant, it could perhaps be explained by the fact that PGTs are responsible in preparing Quality Assurance cases and they may be more familiar with the RCCS than attending urologists.

The main limitation of the present study is the relatively small number of respondents (16 PGTs and 16 attending urologists). Given the relatively small size of urology departments when compared with other surgical specialties, such 
as general surgery and orthopedics, the number of respondents in the present study is reasonable. Nonetheless, this is the first study in its kind in assessing inter-rater variability among urology PGTs and attending urologists. It is possible that when the same survey is administered to a larger cohort of urology PGTs and attending urologists, the inter-rater agreements rates may improve.

\section{Conclusion}

There was good overall agreement among PGTs and attending urologists in application of the RCCS in urology. Therefore, it is appropriate for PGTs to complete the Quality Assurance meeting reports.

Competing interests: None declared.

This paper has been peer-reviewed.

\section{References}

1. Clavien PA, Sanabria JR, Strasberg SM. Proposed classification of complications of surgery with examples of utility in cholecystectomy. Surgery 1992;111:518-26.

2. Dindo D, Demartines N, Clavien PA. Classification of Surgical Complications. A New Proposal with Evaluation in a Cohort of 6336 Patients and Results of a Survey. Ann Surg 2004;240:205-13. http://dx.doi. org/10.1097/01.sla.0000133083.54934.ae

3. Clavien PA, Barkun J, de Oliveira ML, et al. The Clavien-Dindo classification of surgical complications: fiveyear experience. Ann Surg 2009;250:187-96. http://dx.doi.org/10.1097/SLA.0b013e3181b13ca2

4. Donat SM, Shabsigh A, Savage C, et al. Potential impact of postoperative early complications on the timing of adjuvant chemotherapy in patients undergoing radical cystectomy: a high-volume Tertiary Cancer Center Experience. Eur Urol 2009;55:177-85. http://dx.doi.org/10.1016/i.eururo.2008.07.018
5. Constantinides CA, Tyritzis SI, Skolarikos A, et al. Short- and long-term complications of open radical prostatectomy according to the Clavien Classification system. BJU Int 2009;103:336-40. http://dx.doi. org/10.1111/j.1464-410X.2008.08080.x

6. Murphy DG, Kerger M, Crowe $H$, et al. Operative Details and Oncological and Functional Outcome of Robotic-Assisted Laparoscopic Radical Prostatectomy: 400 cases with a Minimum of 12 Months Follow-up. Eur Urol 2009;55:1358-66. http://dx.doi.org/10.1016/i.eururo.2008.12.035

7. Hennus PM, Kroeze SG, Bosch R, et al. Impact of comorbidity on complications after nephrectomy: use of the Clavien Classification of Surgical Complications. BJU Int 2012;110:682-7. http://dx.doi. org/10.1111/j.1464-410X.2011.10889.x

8. Tefekli A, Ali Karadag M, Tepeler K, et al. Classification of Percutaneous Nephrolithotomy Complications Using the Modified Clavien Grading System: Looking for a Standard. Eur Urol 2008;53:184-90. http:// dx.doi.org/10.1016/j.eururo.2007.06.049

9. De La Rosette JJ, Zuazu JR, Tsakiris P, et al. Prognostic Factors and Percutaneous Nephrolithotomy Morbidity: A Multivariate Analysis of a Contemporary Series Using the Clavien Classification. J Urol 2008;180:2489-93. http://dx.doi.org/10.1016/i.juro.2008.08.025

10. Rassweiler JJ, Rassweiler M, Michel M. Classification of Complications: Is the Clavien-Dindo Classification the Gold Standard? Eur Urol 2012;62:256-8. http://dx.doi.org/10.1016/i.eururo.2012.04.028

11. Morgan M, Smith N, Thomas K, et al. Is Clavien the new standard for reporting urological complications? BJU Int 2009;104:434-6. http://dx.doi.org/10.1111/i.1464-410X.2009.08516.x

12. De la Rosette JJMCH, Opondo D, Daels FPJ, et al., on behalf of the CROES PCNL Study Group. Categorisation of complications and validation of the Clavien score for percutaneous nephrolithotomy. Eur Urol 2012;62:256-8. http://dx.doi.org/10.1016/i.eururo.2012.03.055

13. Fleiss JL. Measuring nominal scale agreement among many raters. Psychol Bull 1971;76:378-82. http:// dx.doi.org/10.1037/h0031619

14. Landis JR, Koch GG. The measurement of observer agreement for categorical data. Biometrics 1977;33:159-74. http://dx.doi.org/10.2307/2529310

15. Mitropoulos D, Artibani W, Graefen M, et al. Reporting and Grading of Complications after Urologic Surgical Procedures: An ad hoc EAU Guidelines Panel Assessment and Recommendations. Eur Urol 2012;61:341-9. http://dx.doi.org/10.1016/j.eururo.2011.10.033

16. Sink EL, Leunig M, Zaltz I, et al. Reliability of a Complication Classification System for Orthopedic Surgery. Clin Orthop Relat Res 2012;470:2220-6. http://dx.doi.org/10.1007/s1 1999-012-2343-2

17. Hruza $\mathrm{M}$, Weiss $\mathrm{HO}$, Pini $\mathrm{G}$, et al. Complications in 2200 consecutive laparoscopic prostatectomies: standardized evaluation and analysis of learning curves. Eur Urol 2010;58:733-41. http://dx.doi. org/10.1016/i.eururo.2010.08.024

Correspondence: Dr. Sero Andonian, Assistant Professor of Urology, Royal Victoria Hospital, McGill University Health Centre, 687 avenue des Pins Ouest, Suite S6.92, Montreal, QC H3A 1Al; fax: 514-843-1552; sero.andonian@muhc.mcgill.ca

\begin{tabular}{|c|c|}
\hline Grades & Definition \\
\hline Grade I & $\begin{array}{l}\text { Any deviation from the normal postoperative course without the need for pharmacological treatment or surgical, endoscopic } \\
\text { and radiological interventions. } \\
\text { Allowed therapeutic regimens are: drugs as antiemetics, antipyretics, analgesics, diuretics, electrolytes and physiotherapy. } \\
\text { This grade also includes wound infections opened at the bedside. }\end{array}$ \\
\hline Grade II & $\begin{array}{l}\text { Requiring pharmacological treatment with drugs other than such allowed for grade I complications. Blood transfusions and } \\
\text { total parenteral nutrition are also included. }\end{array}$ \\
\hline Grade III & Requiring surgical, endoscopic or radiological intervention \\
\hline Grade III-a & Intervention not under general anaesthesia \\
\hline Grade III-b & Intervention under general anaesthesia \\
\hline Grade IV & Life-threatening complication (including CNS complications) requiring intermediate care or intensive care unit management \\
\hline Grade IV-a & Single organ dysfunction (including dialysis) \\
\hline Grade IV-b & Multi organ dysfunction \\
\hline Grade V & Death of a patient \\
\hline
\end{tabular}


Elkoushy et al.

\begin{tabular}{|c|c|}
\hline \multicolumn{2}{|c|}{ Appendix 2. Overview of the 20 cases } \\
\hline Case no. & Case description \\
\hline 1 & Post TRUS-guided biopsy sepsis requiring PICC insertion under local anesthesia for home IV antibiotics \\
\hline 2 & $\begin{array}{l}\text { Evisceration post-open radical nephrectomy for renal mass in a 6-year old girl requiring wound re-closure under general } \\
\text { anesthesia }\end{array}$ \\
\hline 3 & Death from dilutional hyponatremia in a 2-year old boy post-PCNL that failed ICU management \\
\hline 4 & Percutaneous pigtail catheter insertion under local anesthesia for management of pneumothorax post partial nephrectomy \\
\hline 5 & Sepsis post transurethral resection of bladder tumor necissitating ICU management including IV antibiotics \\
\hline 6 & $\begin{array}{l}\text { Ureteral obstruction and acute kidney injury post ileal coduit reconstruction requiring percutaneous nephrostomy and } \\
\text { antegrade ureteral stenting under local anesthesia }\end{array}$ \\
\hline 7 & Pyelonephritis post hypospadias repair in a 4-year old boy requiring IV antibiotics \\
\hline 8 & $\begin{array}{l}\text { Hematuria post ureteroscopy requiring cystoscopy and clot evacuation under local anesthesia. Patient continued to bleed } \\
\text { and required cystoscopy and fulguration under general ansethesia in addition to IV antibiotics and blood transfusions. }\end{array}$ \\
\hline 9 & $\begin{array}{l}\text { A12-year old girl developed allergy after receiving IV vancomycin for multi-resistent bacteria. This was managed } \\
\text { conservatively. }\end{array}$ \\
\hline 10 & Deep vein thrombosis post partial nephrectomy requiring anticoagulation with low molecular weight heparin injections \\
\hline 11 & $\begin{array}{l}\text { Blockage of urethral catheter post-orthotopic neobladder reconstruction requiring change of the urethral catheter with } \\
\text { manual irrigations. }\end{array}$ \\
\hline 12 & Hemorrhagic shock post partial nephrectomy requiring re-exploration under general anesthesia to evacuate hematoma \\
\hline 13 & Sepsis post-URS requiring removal of indwelling infected ureteral stent under local anesthesia \\
\hline 14 & $\begin{array}{l}\text { Vertebrobasilar stroke, UTI and pneumonia post transurethral resection of bladder tumor in an 88-year old patient requiring } \\
\text { IV antibiotics }\end{array}$ \\
\hline 15 & $\begin{array}{l}\text { Acute kidney injury post channel transurethral resection of prostate in a } 68 \text {-year old man requiring conservative } \\
\text { management with intravenous medications (not specified) }\end{array}$ \\
\hline 16 & $\begin{array}{l}\text { Extra-peritoneal bladder perforation post URS requiring overnight admission to ICU while being aggressively diuresed and } \\
\text { kept intubated }\end{array}$ \\
\hline 17 & Pelvic collection and death post radical prostatectomy and pelvic node dissection \\
\hline 18 & Clot retention post orthotopic neobladder reconstruction requiring percutaneous instertion of a drain under local anesthesia \\
\hline 19 & Hematoma post circumcision managed conservatively \\
\hline 20 & $\begin{array}{l}\text { Respiratory failure and deep vein thrombosis post PCNL requiring re-intubation, ICU admission and anti-coagulation with } \\
\text { low molecular weigh heparin }\end{array}$ \\
\hline
\end{tabular}

